\title{
Changes in left ventricular electromechanical relations during targeted hypothermia
}

\author{
Kristin Wisløff-Aase ${ }^{1,2^{*}}$ (D) Viesturs Kerans ${ }^{1}$, Kristina Haugaa ${ }^{2,3}$, Per Steinar Halvorsen ${ }^{2,4}$, Helge Skulstad $2,3,4$ \\ and Andreas Espinoza ${ }^{4}$
}

*Correspondence: uxwisk@ous-hf.no

${ }^{1}$ Department

of Anaesthesiology, Oslo

University Hospital -

Rikshospitalet, Nydalen, PO

Box 4950, 0424 Oslo, Norway Full list of author information is available at the end of the article

\begin{abstract}
Background: Targeted hypothermia, as used after cardiac arrest, increases electrical and mechanical systolic duration. Differences in duration of electrical and mechanical systole are correlated to ventricular arrhythmias. The electromechanical window (EMW) becomes negative when the electrical systole outlasts the mechanical systole. Prolonged electrical systole corresponds to prolonged QT interval, and is associated with increased dispersion of repolarization and mechanical dispersion. These three factors predispose for arrhythmias. The electromechanical relations during targeted hypothermia are unknown.

We wanted to explore the electromechanical relations during hypothermia at $33^{\circ} \mathrm{C}$. We hypothesized that targeted hypothermia would increase electrical and mechanical systolic duration without more profound EMW negativity, nor an increase in dispersion of repolarization and mechanical dispersion.
\end{abstract}

Methods: In a porcine model $(n=14)$, we registered electrocardiogram (ECG) and echocardiographic recordings during $38^{\circ} \mathrm{C}$ and $33^{\circ} \mathrm{C}$, at spontaneous and atrial paced heart rate 100 beats/min. EMW was calculated by subtracting electrical systole; QT interval, from the corresponding mechanical systole; QRS onset to aortic valve closure. Dispersion of repolarization was measured as time from peak to end of the ECGT wave. Mechanical dispersion was calculated by strain echocardiography as standard deviation of time to peak strain.

Results: Electrical systole increased during hypothermia at spontaneous heart rate $(p<0.001)$ and heart rate 100 beats $/ \mathrm{min}(p=0.005)$. Mechanical systolic duration was prolonged and outlasted electrical systole independently of heart rate $(p<0.001)$. EMW changed from negative to positive value $(-20 \pm 19$ to $27 \pm 34 \mathrm{~ms}, p=0.001)$. The positivity was even more pronounced at heart rate 100 beats $/ \mathrm{min}(-25 \pm 26$ to $41 \pm 18 \mathrm{~ms}, p<0.001)$. Dispersion of repolarization decreased $(p=0.027$ and $p=0.003$ ), while mechanical dispersion did not differ $(p=0.078$ and $p=0.297)$.

Conclusion: Targeted hypothermia increased electrical and mechanical systolic duration, the electromechanical window became positive, dispersion of repolarization was slightly reduced and mechanical dispersion was unchanged. These alterations may have clinical importance. Further clinical studies are required to clarify whether corresponding electromechanical alterations are accommodating in humans. author(s) and the source, provide a link to the Creative Commons licence, and indicate if changes were made. The images or other third party material in this article are included in the article's Creative Commons licence, unless indicated otherwise in a credit line to the material. If material is not included in the article's Creative Commons licence and your intended use is not permitted by statutory regulation or exceeds the permitted use, you will need to obtain permission directly from the copyright holder. To view a copy of this licence, visit http:// creativecommons.org/licenses/by/4.0/. 
Keywords: Targeted hypothermia, Ventricular arrhythmia, Echocardiography, Myocardial function, Electromechanical relations, Electromechanical window

\section{Background}

Targeted hypothermia $\left(32-36{ }^{\circ} \mathrm{C}\right)$ is recommended in comatose cardiac arrest survivors to improve outcome [1]. However, hypothermia alters cardiac electrical and mechanical function, with reduced heart rate, increased QT interval on the electrocardiogram (ECG) and prolonged mechanical systolic duration [2, 3]. Electrical and mechanical myocardial physiology is closely coupled and under normal circumstances mechanical systole terminates just milliseconds after electrical systole (QT interval) giving a positive electromechanical window (EMW). In certain conditions where the QT interval, outlasts the mechanical systole, this leads to negative EMW. QT interval prolongation is associated with dispersion of repolarization and mechanical dispersion. An increased QT interval, $[4,5]$ electromechanical window negativity, dispersion of repolarization and mechanical dispersion are correlated to arrhythmic events under a wide diversity of clinical conditions [6-10].

However, there has not been observed increased incidence of adverse ventricular arrhythmic events during treatment with targeted hypothermia in cardiac arrest survivors [11-13]. EMW, dispersion of repolarization and mechanical dispersion are all novel parameters with clinical relevance to understand the effect of hypothermia and are not previously analysed and described. The present experimental animal study aimed to explore the electromechanical relations during targeted hypothermia at $33^{\circ} \mathrm{C}$. We hypothesized that hypothermia increases electrical and mechanical systolic duration without more profound EMW negativity independently of heart rate. Furthermore, we hypothesized that dispersion of repolarization and mechanical dispersion, remain unchanged during hypothermia.

\section{Methods}

\section{Animal model}

The experiment was performed in an open chest porcine model. Data for the present study were collected from experiment series published in two previous articles [3, 14]. The open model facilitated recording of high quality echocardiographic images needed for the study, otherwise difficult to obtain in the pigs.

The study was approved by Nationals Animal Research Authority of Norway (trial registration number: FOTS 3866) and carried out in accordance to the European Convention for the protection of vertebrate animals used for experimental and other scientific purposes, the European Union Directive 2010/63/EU [15].

\section{Animal preparations}

The animals ( $n=14$, Norwegian land race swine, mean weight $52 \pm 4.3 \mathrm{~kg}$ ) were fasting overnight aside from free water access. They were pre-medicated by an intramuscular injection with ketamine $(20 \mathrm{mg} / \mathrm{kg})$, azaperone $(3 \mathrm{mg} / \mathrm{kg})$ and atropine $(20 \mu \mathrm{g} /$ $\mathrm{kg})$. Anaesthesia was induced with intravenous pentobarbital $(3 \mathrm{mg} / \mathrm{kg})$ and morphine $(2 \mathrm{mg} / \mathrm{kg})$, and maintained with morphine infusion $(1-2 \mathrm{mg} / \mathrm{kg} / \mathrm{h})$ and isoflurane 
inhalation (1-1.5\%). Neuromuscular blocking agents were not used. Level of anaesthesia was monitored by continually haemodynamic measurements and observation of clinical signs. When the protocol was finished, the animals were euthanatized by bolus infusion of $80 \mathrm{mmol}$ potassium chloride and $1000 \mathrm{mg}$ pentobarbital. The animals were mechanically ventilated via a tracheostomy tube by a fraction of air/oxygen $\left(\mathrm{FiO}_{2} \mathrm{0.4}\right)$, with tidal volumes of $10-15 \mathrm{ml} / \mathrm{kg}$ and surgically prepared with sternotomy as previously reported $[3,14]$. Three-lead ECG was obtained by skin leads. Pacemaker leads were sutured to the right atrium. For temperature control, a water circulated catheter (Cool Line; Zoll, Chelmsford, MA, USA) was inserted into the inferior vena cava by cannulation of the left femoral vein and connected to the thermal regulation system (Coolgard 3000; Zoll). A pulmonary artery catheter (Swan-Ganz CCO; Edwards Lifesciences, Irvin, CA, USA) was inserted through the right jugular vein to measure central temperature and haemodynamic variables. Left ventricular pressure was measured by a micro-manometer pressure transducer (MPR-500; Millar Instruments, Houston, TX) placed via the right carotid artery. A Vivid 7 scanner (GE Vingmed Ultrasound, Horten, Norway) with $2.5 / 2.75 \mathrm{MHz}$ probe directly on the heart, was used for echocardiographic and Doppler recordings.

Haemodynamic data regarding systolic and diastolic function obtained from the experiment has been published [3, 14], but is included as background data in the current manuscript. All data presented concerning the electromechanical relations, has been analysed for this study.

\section{Measurements and analysis}

Measurements were obtained at body temperature $38{ }^{\circ} \mathrm{C}$ (normal body temperature of the pigs) and $33{ }^{\circ} \mathrm{C} .33{ }^{\circ} \mathrm{C}$ was chosen representing median temperature recommended from cardiac resuscitation guidelines at that time, with a targeted temperature of $32-34{ }^{\circ} \mathrm{C}$ [16]. Measurements were made at both spontaneous heart rate (HR) and during atrial pacing, 100 beats/min (bpm). All measurements and recordings were made in three echocardiographic views over three consecutive heart cycles and the mean values were calculated. The pacing enabled measurements at heart rate $100 \mathrm{bpm}$, thereby compensating for individual variability and hypothermia induced heart rate reduction. ECG, two-dimensional (2D) and Doppler echocardiography were recorded and analysed offline (EchoPac version 202, GE Healthcare, Horten, Norway).

\section{Calculations of the electrical events}

The ECG lead II was used for electrical measurements. The electrical systole (QT interval), was measured from onset of QRS to end of $\mathrm{T}$ wave (Te) in ECG. The QT interval was heart rate corrected according to the Bazett's formula (QTc) [17]. Te was determined by using the manual tangent method and defined as the intersection of the isoelectric line with the tangent to the steepest downslope of the $T$ wave. Dispersion of repolarization was measured as variation in $\mathrm{T}$ peak to $\mathrm{T}$ end duration (TpTe). Tp was defined as the first maximum positive or negative deflection of the $\mathrm{T}$ wave from the isoelectric line [18]. TpTe was corrected for heart rate using a modified Bazett's formula $(\mathrm{Tp} T e \mathrm{C}=\mathrm{Tp} \mathrm{Te} / \sqrt{ } \mathrm{RR})$. 


\section{Calculation of the mechanical events}

From echocardiographic apical 4-chamber long axis view, mitral and aortic valve opening and closing were recorded. Isovolumic contraction time (IVCT) and isovolumic relaxation time (IVRT) were measured in long axis view from mitral valve closing (MVC) to aortic valve opening (AVO) and aortic valve closing (AVC) to mitral valve opening (MVO), respectively. Ejection time was measured as the duration of the pulsed wave Doppler signal in left ventricular outflow tract $\left(\mathrm{ET}_{\mathrm{PW}}\right)$ and from AVO to AVC. The interval from onset of QRS to the registered AVC represented the duration of the mechanical systole (QAVC). EMW was calculated by subtracting the electrical systole from the duration of the mechanical systole in the same heartbeat, QAVC-QT interval (Fig. 1).

\section{Global cardiac function}

Left ventricular volumes were measured from 2D echocardiographic images (apical 4and 2-chamber views), and ejection fraction was calculated by the modified Simpson biplane method. Systolic velocity was recorded from mitral ring tissue Doppler velocity images in apical 4-chamber views. Cardiac output was measured by pulmonary artery catheter thermodilution and stroke volume was calculated. Peak systolic left ventricular pressure was recorded by the micro-manometer catheter placed in the left ventricle.

\section{Regional strain and mechanical dispersion}

Longitudinal strain was obtained by speckle tracking echocardiography from the basal and mid segments in three apical left ventricular projections (4-chamber, 2-chamber and long axis, frame rate $63 \pm 15 \mathrm{~ms}$ ). The endocardial border was traced manually, and region of interest was adjusted to fit the myocardial thickness. Segments that failed to track were manually adjusted, and if subsequent failing the segments were excluded. The echocardiographic probe was directly placed on the heart with a subsequent loss of the apical segments, whereof peak strain was derived from 12 segments. Time to peak strain

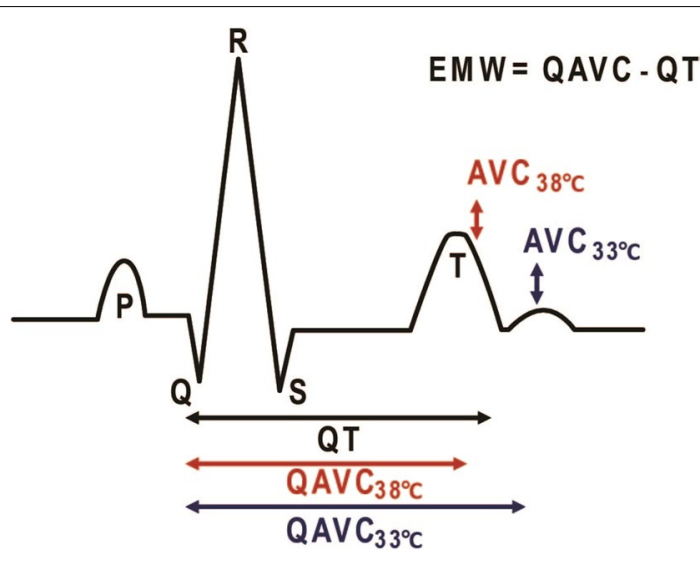

Fig. 1 ECG with remarked echocardiographic timing. A schematic drawing of an ECG signal combined with remarked echocardiographic timing of the aortic valve closure (AVC). QT interval is prolonged at $33^{\circ}$ schematic drawing of an ECG si Electromechanical window (EMW) is calculated as EMW=QAVC-QT 
Table 1 Haemodynamic variables

\begin{tabular}{|c|c|c|c|c|c|c|}
\hline & \multicolumn{3}{|c|}{ Spontaneous HR } & \multicolumn{3}{|c|}{ HR 100 bpm } \\
\hline & $38^{\circ} \mathrm{C}$ & $33^{\circ} \mathrm{C}$ & $p$ & $38^{\circ} \mathrm{C}$ & $33^{\circ} \mathrm{C}$ & $p$ \\
\hline $\mathrm{MAP}(\mathrm{mmHg})$ & $62 \pm 8$ & $53 \pm 9$ & 0.009 & $65 \pm 9$ & $54 \pm 7$ & 0.007 \\
\hline SVR(dynes $/ \mathrm{s} / \mathrm{cm}^{5}$ ) & $930 \pm 181$ & $966 \pm 166$ & 0.591 & $864 \pm 141$ & $915 \pm 107$ & 0.325 \\
\hline $\operatorname{LVP}(\mathrm{mmHg})$ & $84 \pm 6$ & $69 \pm 11$ & $<0.001$ & $86 \pm 6$ & $67 \pm 11$ & $<0.001$ \\
\hline $\mathrm{CO}(1 / \mathrm{min})$ & $4.7 \pm 0.9$ & $3.7 \pm 0.7$ & 0.001 & $5.3 \pm 0.6$ & $4.0 \pm 0.8$ & $<0.001$ \\
\hline $\mathrm{SV}(\mathrm{ml} /$ beat $)$ & $54 \pm 7$ & $50 \pm 11$ & 0.241 & $53 \pm 7$ & $40 \pm 8$ & $<0.001$ \\
\hline $\mathrm{EF}(\%)$ & $57 \pm 6$ & $55 \pm 8$ & 0.309 & $60 \pm 6$ & $50 \pm 5$ & $<0.001$ \\
\hline SS(\%) & $32 \pm 7$ & $23 \pm 6$ & $<0.001$ & $27 \pm 7$ & $17 \pm 5$ & $<0.001$ \\
\hline SL(\%) & $30 \pm 7$ & $23 \pm 7$ & $<0.001$ & $26 \pm 7$ & $17 \pm 3$ & $<0.001$ \\
\hline $\mathrm{s}^{\prime}(\mathrm{m} / \mathrm{s})$ & $0.06 \pm 0.01$ & $0.05 \pm 0.01$ & 0.023 & $0.06 \pm 0.01$ & $0.05 \pm 0.01$ & 0.012 \\
\hline
\end{tabular}

Data are expressed as Mean \pm SD

MAP mean arterial pressure, SVR systemic vascular resistance, LVP left ventricular pressure, CO cardiac output, SV stroke volume, EF ejection fraction, SS longitudinal septal LV strain, $S L$ longitudinal lateral LV strain, $s^{\prime}$ systolic velocity

in each segment was defined as the time from Q onset on ECG to peak longitudinal strain in three cycles and averaged. Mechanical dispersion was defined as the standard deviation of time to peak negative strain [19] in the 12 left ventricular segments. Septal and lateral strains were measured from basal segments in 4-chamber view.

\section{Observer variability}

Doppler registered QT and QAVC were re-measured by the same observer to assess intraobserver repeatability. A second observer measured the same variables in seven random selected animals to assess interobserver reproducibility.

\section{Statistical analyses}

Statistical analyses were performed in SPSSv.25 software (SPSS, Inc., Chicago, IL, USA). Parametric data are presented as mean \pm standard deviation. Data from normothermia and hypothermia at spontaneous and heart rate $100 \mathrm{bpm}$ were compared by Student's $t$-test. P-value, $p<0.05$ was considered statistically significant. Intra- and interobserver variations were analysed by using intraclass correlation coefficient concerning single measures [20].

\section{Results}

All recordings were of good quality. Three animals had a spontaneous heart rate above $100 \mathrm{bpm}$ at $38{ }^{\circ} \mathrm{C}$, and were not paced during normothermia. One animal did not receive pacing due to malfunction of the pacemaker electrode.

\section{Haemodynamic parameters and myocardial function during hypothermia}

During hypothermia mean arterial pressure and left ventricular pressure were reduced at both spontaneous rhythm and heart rate $100 \mathrm{bpm}$ (Table 1). Strain, systolic velocity and cardiac output decreased. Stroke volume and ejection fraction remained unchanged at spontaneous heart rate, but decreased at $100 \mathrm{bpm}$, indicating that the left ventricle was less tolerant to increased frequency during hypothermia $[3,14]$. 
Table 2 Electrocardiographic variables

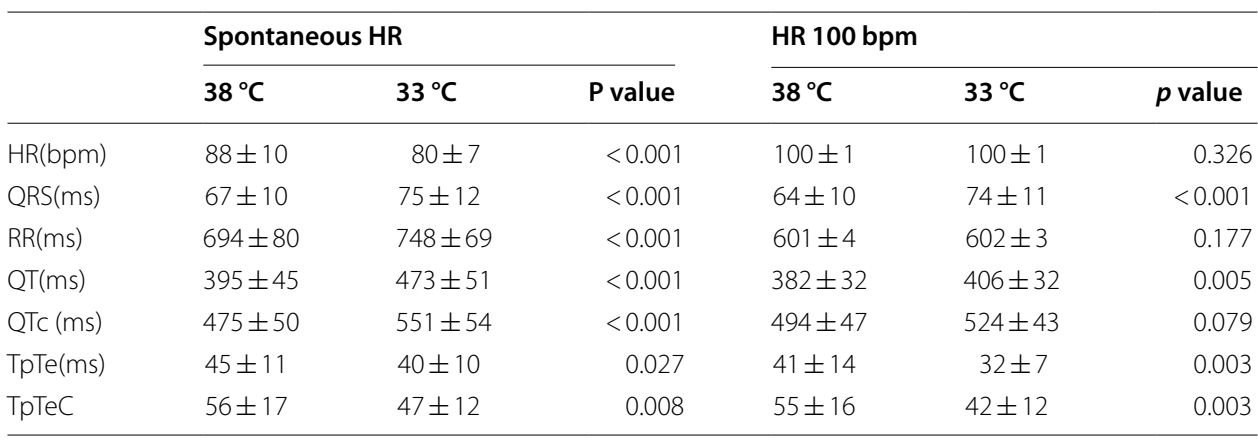

Data are expressed as Mean \pm SD

$H R$ heart rate, QRS QRS on ECG, RR cardiac cycle interval, QT QT interval, QTC QT interval corrected for HR, TpTe T wave peak to $T$ wave end duration, dispersion of repolarization, TpTeC TpTe corrected for heart rate

\section{Electromechanical changes at spontaneous heart rate during hypothermia}

Hypothermia reduced spontaneous heart rate, prolonged QRS duration and increased QT interval (Table 2). QAVO, IVCT and IVRT did not change. Both the $\mathrm{ET}_{\mathrm{PW}}$ and the echocardiographic recorded interval from AVO to AVC increased. QAVC increased accordingly, and more than the QT interval ( $42 \%$ vs $20 \%$, respectively). The mechanical systolic duration outlasted the electrical systole, and EMW changed from $-20 \pm 19$ to $27 \pm 34 \mathrm{~ms}(p=0.001)$ (Fig. 2). Dispersion of repolarization was reduced also when corrected for heart rate (Table 2). Mechanical dispersion remained unchanged compared to normothermia (Table 3).

\section{Electromechanical changes at heart rate $100 \mathrm{bpm}$ during hypothermia}

At heart rate $100 \mathrm{bpm}$, electromechanical alterations during hypothermia were similar as during spontaneous heart rate. The QRS complex and the QT interval was widened (Table 2). The mechanical systole was prolonged, but shorter compared to the duration at spontaneous heart rate (Table 3). The QAVC increased with 34\% and the QT interval with $6 \%$ though the EMW positivity was more pronounced during heart rate $100 \mathrm{bpm}$, $-25 \pm 26$ to $41 \pm 18 \mathrm{~ms},(p=0.001)$ (Fig. 2). Dispersion of repolarization was reduced (Table 1) and mechanical dispersion unchanged at $100 \mathrm{bpm}$ (Table 3). There were no differences in level of significance for EMW, dispersion of repolarization or mechanical dispersion measured at spontaneous heart rate or at heart rate $100 \mathrm{bpm}$ during hypothermia (Table 4).

\section{Observer variability}

Intraobserver correlation coefficient for QT and QAVC were 0.99 (95\% confidence interval (CI) $0.98-1.0)$ and 0.99 (95\% CI 0.99-1.0). Interobserver correlation coefficient for the same parameters were 0.99 ( $95 \%$ CI $0.98-1.0$ ) and 0.99 (95\% CI 0.77-1.0).

\section{Discussion}

In this experimental study, targeted hypothermia increased both electrical and mechanical systolic duration. Indeed, the mechanical systole outlasted the electrical systole independently of heart rate and therefore the EMW became positive. Dispersion of 

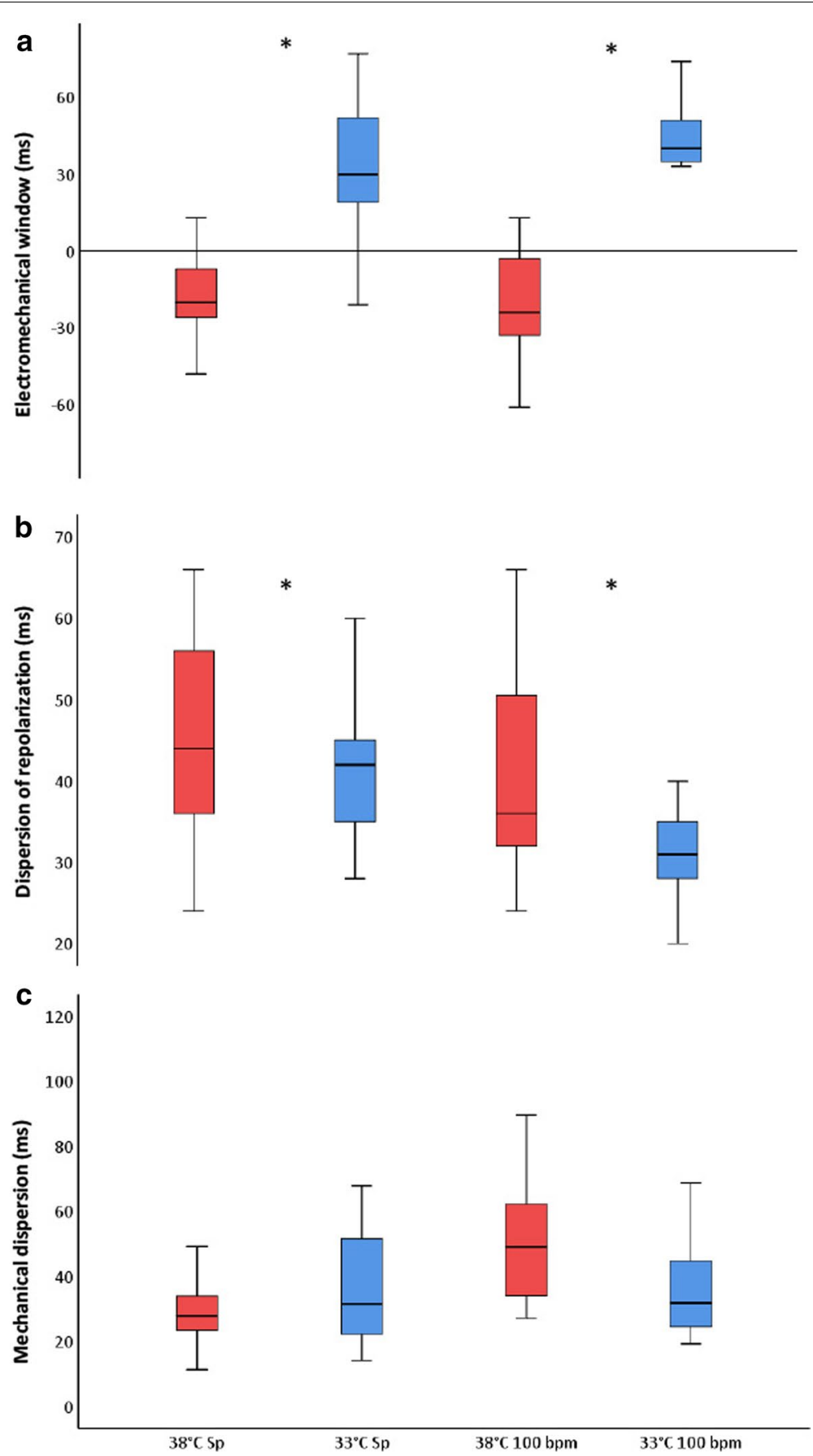

Fig. 2 Electromechanical window, dispersion of repolarization and mechanical dispersion. Electromechanical window $(\mathbf{a})$, dispersion of repolarization $(\mathbf{b})$ and mechanical dispersion (c) during normothermia $\left(38^{\circ} \mathrm{C}\right)$ and hypothermia $\left(33^{\circ} \mathrm{C}\right)$ at spontaneous $(\mathrm{Sp})$ and heart rate $100 \mathrm{bpm}$. The plots are computed from $13(\mathbf{a})$ and 14 $(\mathbf{b}, \mathbf{c})$ animals at spontaneous heart rate, and $12(\mathbf{a}) / 13(\mathbf{b}, \mathbf{c})$ animals for paced heart rate. Asterisk indicates statistical significance, $p<0.05$ 
Table 3 Mechanical and electromechanical variables

\begin{tabular}{|c|c|c|c|c|c|c|}
\hline & \multicolumn{3}{|c|}{ Spontaneous HR } & \multicolumn{3}{|c|}{ HR 100 bpm } \\
\hline & $38^{\circ} \mathrm{C}$ & $33^{\circ} \mathrm{C}$ & $p$ & $38^{\circ} \mathrm{C}$ & $33^{\circ} \mathrm{C}$ & $p$ \\
\hline $\mathrm{QAVO}(\mathrm{ms})$ & $91 \pm 11$ & $97 \pm 10$ & 0.071 & $89 \pm 8$ & $99 \pm 7$ & 0.076 \\
\hline QAVC(ms) & $353 \pm 17$ & $501 \pm 24$ & $<0.001$ & $341 \pm 20$ & $456 \pm 11$ & $<0.001$ \\
\hline AVO-AVC(ms) & $275 \pm 47$ & $379 \pm 27$ & $<0.001$ & $257 \pm 20$ & $336 \pm 17$ & $<0.001$ \\
\hline $\mathrm{ET}_{\mathrm{pw}}(\mathrm{ms})$ & $302 \pm 36$ & $382 \pm 43$ & 0.001 & $282 \pm 22$ & $344 \pm 49$ & 0.014 \\
\hline IVCT(ms) & $39 \pm 11$ & $43 \pm 12$ & 0.409 & $45 \pm 2$ & $51 \pm 10$ & 0.301 \\
\hline IVRT(ms) & $62 \pm 13$ & $71 \pm 20$ & 0.081 & $64 \pm 19$ & $67 \pm 21$ & 0.685 \\
\hline $\mathrm{EMW}(\mathrm{ms})$ & $-20 \pm 19$ & $27 \pm 34$ & 0.001 & $-25 \pm 26$ & $41 \pm 18$ & $<0.001$ \\
\hline $\mathrm{MD}(\mathrm{ms})$ & $29 \pm 11$ & $36 \pm 17$ & 0.078 & $47 \pm 16$ & $40 \pm 23$ & 0.297 \\
\hline
\end{tabular}

Data are expressed as mean $\pm S D$

QAVO Q onset to aortic valve opening, QAVC Q onset to aortic valve closing, AVO-AVC aortic valve opening to aortic valve closing, $E T_{p w}$ left ventricular outflow tract ejection time, Doppler registered, IVCT isovolumic contraction time, IVRT isovolumic relaxation time, EMW electromechanical window: QAVC - QT, MD mechanical dispersion

Table 4 Spontaneous heart rate versus heart rate $100 \mathrm{bpm}$

\begin{tabular}{lclrrrr}
\hline & $\mathbf{3 8}^{\circ} \mathbf{C s p}$ & $\mathbf{3 8}^{\circ} \mathbf{C p m}$ & $\boldsymbol{p}$ & $\mathbf{3 3}^{\circ} \mathbf{C s p}$ & $\mathbf{3 3}^{\circ} \mathbf{C p m}$ & $\boldsymbol{p}$ \\
\hline $\mathrm{EMW}(\mathrm{ms})$ & $-20 \pm 19$ & $-25 \pm 26$ & 0.281 & $27 \pm 34$ & $41 \pm 18$ & 0.099 \\
$\mathrm{TpTeC}(\mathrm{ms})$ & $56 \pm 17$ & $55 \pm 16$ & 0.992 & $47 \pm 12$ & $42 \pm 12$ & 0.053 \\
$\mathrm{MD}(\mathrm{ms})$ & $29 \pm 11$ & $47 \pm 16$ & $<0.001$ & $36 \pm 17$ & $40 \pm 23$ & 0.632 \\
\hline
\end{tabular}

Data are expressed as mean \pm SD

$s p$ spontaneous heart rate, $p m$ atrial pacing; $100 \mathrm{bpm}, E M W$ electromechanical window: QAVC - QT, TpTeC dispersion of repolarization, corrected for heart rate, $M D$ mechanical dispersion

repolarization was slightly reduced, and mechanical dispersion was unchanged, at both spontaneous and at heart rate $100 \mathrm{bpm}$.

\section{The shift in electromechanical window}

Cardiac arrhythmic diseases are primarily perceived as electrical disorders. Prolonged QT interval with EMW negativity is an independent pro-arrhythmic predictor. This arrhythmogenicity may be a consequence not only of electrical alterations, but likely also of mechanical influences. In one study increased EMW negativity for any QTc in long QT syndrome was found, indicating an electrical-independent mechanical influence [6]. In our study, we found that despite the increased QT interval there was significant change to EMW positivity during hypothermia, due to the even more prolonged mechanical systolic duration. The QRS interval and IVCT were slightly prolonged, but gave only a small contribution to the extended QAVC at spontaneous heart rate. The increase in AVO to AVC interval was the main contributor to the prolonged mechanical systolic duration. These results support the theory that electromechanical alterations during targeted hypothermia may be consequences of mechanical independent influences as well. 
In our in vivo model, baseline EMW was slightly negative at both heart rates. The normal value for EMW in land race pigs during normothermia is unknown, but an open chest model can lead to a prolonged QT interval which may contribute to EMW negativity [21]. In an ex vivo model, isolated Langendorff-perfused Göttingen minipig hearts baseline EMW was $134 \mathrm{~ms}$ [22]. However, an ex vivo model may have substantial cardiac electromechanical influence [23]. During hypothermia we found that EMW changed from negative to positive. A corresponding tendency with preserved or increased EMW during cooling is previously reported [24, 25].

\section{Electrical dispersion}

TpTe is a marker for dispersion of repolarization with a strong association to arrhythmic risk. Whether the ECG measured dispersion represents transmural repolarization, global or both is still not clarified [26, 27]. In our model, single lead ECG from lead II was used for TpTe measurements. We found no increase, but rather a reduction in dispersion of repolarization during hypothermia. Previously published experimental and clinical results have shown no significant increase in transmural dispersion of repolarization during moderate hypothermia despite increased action potential duration and slowing of conduction velocity $[28,29]$. Inducing repolarization abnormalities by ventricular pacing did neither increase risk of arrhythmia at $33^{\circ} \mathrm{C}$ compared to normothermia and pro-arrhythmic parameters such as slowing of conduction velocity and prolonged action potential duration were attenuated at $33^{\circ} \mathrm{C}$ [30]. Experimental studies actually indicate a direct anti arrhythmic effect on the myocardial cells by increased membrane stability during targeted hypothermia $[5,31]$. However, at lower temperatures, experimental studies with targeted temperature have shown increased dispersion of repolarization [28, 32]. Our findings are in accordance with comparable experimental data. The reported slightly reduced dispersion of repolarization at $33^{\circ} \mathrm{C}$ in our study may be a consequence of the registered lead II which represents global repolarization with less correlation to transmural dispersion.

\section{Mechanical dispersion}

The prolongation and slowing of systolic contraction during targeted hypothermia at $33{ }^{\circ} \mathrm{C}$ is previously described $[3,14]$. However, it is not known whether this is due to asynchronous activation and relaxation of left ventricular segments with a prolonged systole, or as synchronous slowed prolongation of all segments. Pathological mechanical dispersion occurs as a mechanical consequence of electrical alterations or myocardial dysfunction [33] and correlates with increased QT interval, contraction duration and EMW negativity $[34,35]$.

Overall, we found no increase in mechanical dispersion but slightly prolonged ventricular depolarization, prolonged QT interval with reduced dispersion of repolarization and increased ventricular contraction duration. The registered increase in contraction duration may be explained by a synchronous contraction prolongation since there was no increase in dispersion of repolarization. However, it is still somewhat unclear how electrical and mechanical activities are coupled. The absence of mechanical dispersion does not necessarily indicate a synchronous pattern. Mechanical dispersion is measured as SD of time to peak systolic strain. Contraction end is not taken into account, which 
may be displaced. Hypothermia induced electrical delay with increased action potentials or affected electrical conduction in the myocardium, might have an additional coexisting influence on the systolic contraction pattern. Based on our experiments it is difficult to draw any conclusion regarding either mechanism.

\section{Clinical implications}

The beneficial and harmful effects of targeted hypothermia and the optimal temperature are not completely clarified. After cardiac arrest it might be difficult to distinguish whether myocardial dysfunction, arrhythmias or other adverse events are due to myocardial injury or to hypothermia itself. This may contribute to a possible restrain regarding clinical implementation [36, 37]. Our experimental model describes changes in the electromechanical relations during hypothermia in healthy animal hearts with a clinical translational value but confined by the experimental setting with anatomical and physical differences and unexposed pathology compared to patients with cardiac arrest. Our findings in this experimental model indicate an electromechanical change that could infer decreased arrhythmia susceptibility during hypothermia at $33{ }^{\circ} \mathrm{C}$ but the isolated effect from targeted hypothermia on electromechanical relations in healthy pig hearts should be interpreted cautiously. However, this study makes an important contribution to further explore the effect of hypothermia on the electromechanical relations. Clinical studies are required to clarify whether these electromechanical alterations during hypothermia are accommodating in humans.

\section{Limitations}

Three-lead ECG were connected to the echocardiographic scanner. TpTe interval measurements from the bipolar limb lead II have limitations as discussed above. ECG TpTe interval from bipolar limb leads is thought to represent global dispersion, including apicobasal and interventricular dispersion of repolarization. Transmural dispersion of repolarization is most represented in precordial leads and is suggested to be the preferred leads when estimating arrhythmic risk [26]. Our study protocol was not designed to evaluate arrhythmic risk, but to study electromechanical relations. Digital ECG and automatic analyses with multi-lead representations may have made the results more valid, but were not available due to the already accomplished animal study. The animals in our model represented their own control with no other adjustment than temperature and HR during the experiments. The methods used to identify electrical intervals were identical for all measurements and the reproducibility of the measurements was good.

The open chest model may have altered the preload and afterload conditions [21]. However, we analysed the absolute change in the parameters during stable phases. The pigs were anaesthetized with isoflurane and morphine after induction with pentobarbital. This is routinely applied and recommended in experimental settings when cardiothoracic surgery is needed [23], despite the well-known pharmacological impact on the cardiovascular system and the autonomic balance [38-40]. The anaesthetics were maintained at the same rate with no modifications throughout the experiment. In addition, the possible pharmacological heart rate effect was superseded by the temperature effect, and compensated by atrial paced heart rate $100 \mathrm{bpm}$ during normo- and hypothermia. 


\title{
Conclusion
}

Targeted hypothermia increased the duration of both the electrical and mechanical systole. The prolonged duration of the mechanical systole was relatively greater and outlasted the electrical systole at hypothermia. This led to a positive EMW. Hypothermia slightly reduced dispersion of repolarization, while mechanical dispersion remained unchanged. Further clinical studies are required to elucidate whether these electromechanical relations during hypothermia are presented in humans.

\begin{abstract}
Abbreviations
ECG: Electrocardiogram; QT interval: Electrical systole; QTc: Corrected QT interval; bpm: Beats per minute; 2D: Two dimensional; EMW: Electromechanical window; TpTe: T wave peak to T wave end; electrical dispersion of repolarization; TpTeC: Corrected TpTe interval; AVO: Aortic valve opening; AVC: Aortic valve closing; ET pw: Ejection time by pulsed wave Doppler signal in left ventricular outflow tract; QAVC: Q onset to aortic valve closing; mechanical systole; MAP: Mean arterial pressure; SVR: Systemic vascular resistance; LVP: Left ventricular pressure; CO: Cardiac output; SV: Stroke volume; EF: Ejection fraction; SS: Strain septal; SL: Strain longitudinal; s': Mitral ring systolic velocity; HR: Heart rate; QRS: QRS complex on ECG; RR: Interval from R to R between two QRS complexes; IVCT: Isovolumic contraction time; IVRT: Isovolumic relaxation time; MD: Mechanical dispersion.
\end{abstract}

\section{Acknowledgements}

This work was performed at The Intervention Centre, Oslo University Hospital. The authors thank the staff at the animal research veterinary, the Department of Comparative Medicine for care of the animals and The Intervention Centre for assistance during the experiments. We are grateful to Marte Sævik (MD) who performed measurements for assessment of interobserver reproducibility.

\section{Authors' contributions}

KWA analysed and interpreted data. KWA drafted the manuscript with significant contributions from AE and HS. All authors have been involved in planning the study design, and have read and approved the final manuscript.

\section{Funding}

There was no external funding of the project. The study was administratively supported by the Intervention Centre, Oslo University Hospital.

\section{Availability of data and materials}

The datasets used and analysed during the current study are available from the corresponding author on reasonable request.

\section{Ethics approval and consent to participate}

The study was approved by Nationals Animal Research Authority of Norway (trial registration number: FOTS 3866) and carried out in accordance to the European Convention for the protection of vertebrate animals used for experimental and other scientific purposes, the European Union Directive 2010/63/EU [15] and the ARRIVE guidelines [41].

\section{Consent for publication}

Not applicable.

\section{Competing interests}

The authors declare that they have no competing interests.

\section{Author details}

${ }^{1}$ Department of Anaesthesiology, Oslo University Hospital - Rikshospitalet, Nydalen, PO Box 4950, 0424 Oslo, Norway. ${ }^{2}$ Institute of Clinical Medicine, Faculty of Medicine, University of Oslo, Oslo, Norway. ${ }^{3}$ Department of Cardiology, Oslo University Hospital, Oslo, Norway. ${ }^{4}$ The Intervention Centre, Oslo University Hospital, Oslo, Norway.

Received: 31 July 2020 Accepted: 2 December 2020

Published online: 14 December 2020

\section{References}

1. Nolan JP, Soar J, Cariou A, Cronberg T, Moulaert VR, Deakin CD, Bottiger BW, Friberg H, Sunde K, Sandroni C (2015) European Resuscitation Council and European Society of Intensive Care Medicine Guidelines for Post-resuscitation care 2015: Section 5 of the European Resuscitation Council Guidelines for resuscitation 2015. Resuscitation 95:202-222

2. Emslie-Smith D, Sladden GE, Stirling GR (1959) The significance of changes in the electrocardiogram in hypothermia. Br Heart J 21:343-351

3. Espinoza A, Kerans V, Opdahl A, Skulstad H, Halvorsen PS, Bugge JF, Fosse E, Edvardsen T (2013) Effects of therapeutic hypothermia on left ventricular function assessed by ultrasound imaging. J Am Soc Echocardiogr 26:1353-1363

4. Algra A, Tijssen JG, Roelandt JR, Pool J, Lubsen J (1991) QTc prolongation measured by standard 12-lead electrocardiography is an independent risk factor for sudden death due to cardiac arrest. Circulation 83:1888-1894 
5. Polderman KH (2009) Mechanisms of action, physiological effects, and complications of hypothermia. Crit Care Med 37:S186-202

6. ter Bekke RM, Haugaa KH, van den Wijngaard A, Bos JM, Ackerman MJ, Edvardsen T, Volders PG (2015) Electromechanical window negativity in genotyped long-QT syndrome patients: relation to arrhythmia risk. Eur Heart 36:179-186

7. Watanabe N, Kobayashi Y, Tanno K, Miyoshi F, Asano T, Kawamura M, Mikami Y, Adachi T, Ryu S, Miyata A, Katagiri T (2004) Transmural dispersion of repolarization and ventricular tachyarrhythmias. J Electrocardiol 37:191-200

8. Hetland M, Haugaa KH, Sarvari SI, Erikssen G, Kongsgaard E, Edvardsen T (2014) A novel ECG-index for prediction of ventricular arrhythmias in patients after myocardial infarction. Ann Noninvasive Electrocardiol 19:330-337

9. Haland TF, Almaas VM, Hasselberg NE, Saberniak J, Leren IS, Hopp E, Edvardsen T, Haugaa KH (2016) Strain echocardiography is related to fibrosis and ventricular arrhythmias in hypertrophic cardiomyopathy. Eur Heart J Cardiovasc Imaging 17:613-621

10. Haugaa KH, Smedsrud MK, Steen T, Kongsgaard E, Loennechen JP, Skjaerpe T, Voigt JU, Willems R, Smith G, Smiseth OA, Amlie JP, Edvardsen T (2010) Mechanical dispersion assessed by myocardial strain in patients after myocardial infarction for risk prediction of ventricular arrhythmia. JACC Cardiovasc Imaging 3:247-256

11. Nielsen N, Sunde K, Hovdenes J, Riker RR, Rubertsson S, Stammet P, Nilsson F, Friberg H (2011) Adverse events and their relation to mortality in out-of-hospital cardiac arrest patients treated with therapeutic hypothermia. Crit Care Med 39:57-64

12. Storm C, Hasper D, Nee J, Joerres A, Schefold JC, Kaufmann J, Roser M (2011) Severe QTc prolongation under mild hypothermia treatment and incidence of arrhythmias after cardiac arrest-a prospective study in 34 survivors with continuous Holter ECG. Resuscitation 82:859-862

13. Bernard SA, Gray TW, Buist MD, Jones BM, Silvester W, Gutteridge G, Smith K (2002) Treatment of comatose survivors of out-of-hospital cardiac arrest with induced hypothermia. N Engl J Med 346:557-563

14. Kerans V, Espinoza A, Skulstad H, Halvorsen PS, Edvardsen T, Bugge JF (2015) Systolic left ventricular function is preserved during therapeutic hypothermia, also during increases in heart rate with impaired diastolic filling. Intensive Care Med Exp 3:41

15. Olsson IAS, Silva SPD, Townend D, Sandoe P (2016) Protecting animals and enabling research in the European Union: an overview of development and Implementation of Directive 2010/63/EU. ILAR J 57:347-357

16. Nolan JP, Morley PT, Hoek TL, Hickey RW (2003) Therapeutic hypothermia after cardiac arrest. An advisory statement by the Advancement Life support Task Force of the International Liaison committee on Resuscitation. Resuscitation 57:231-235

17. Bazett HC (1920) An analysis of the time relations of electrocardiograms. Heart 7:353-370

18. Rosenthal TM, Masvidal D, Abi Samra FM, Bernard ML, Khatib S, Polin GM, Rogers PA, Xue JQ, Morin DP (2018) Optimal method of measuring the T-peak to T-end interval for risk stratification in primary prevention. Europace 20:698-705

19. Haugaa KH, Edvardsen T, Leren TP, Gran JM, Smiseth OA, Amlie JP (2009) Left ventricular mechanical dispersion by tissue Doppler imaging: a novel approach for identifying high-risk individuals with long QT syndrome. Eur Heart J 30:330-337

20. Popovic ZB, Thomas JD (2017) Assessing observer variability: a user's guide. Cardiovasc Diagn Ther 7:317-324

21. Lubberding AF, Sattler SM, Flethøj M, Tfelt-Hansen J, Jespersen T (2020) Comparison of hemodynamics, cardiac electrophysiology, and ventricular arrhythmia in an open- and a closed-chest porcine model of acute myocardial infarction. Am J Physiol Heart Circ Physiol 318:H391-h400

22. Laursen M, Grunnet M, Olesen SP, Jespersen T, Mow T (2011) Keeping the rhythm—pro-arrhythmic investigations in isolated Göttingen minipig hearts. J Pharmacol Toxicol Methods 64:134-144

23. Swindle MM, Smith AC (2015) Swine in the laboratory: surgery, anesthesia, imaging, and experimental techniques. CRC Press, Boca Raton

24. Guns PJ, Johnson DM, Op V, den Bosch J, Weltens E, Lissens J (2012) The electro-mechanical window in anaesthetized guinea pigs: a new marker in screening for Torsade de Pointes risk. Br J Pharmacol 166:689-701

25. van der Linde HJ, Van Deuren B, Somers Y, Loenders B, Towart R, Gallacher DJ (2010) The Electro-Mechanical window: a risk marker for Torsade de Pointes in a canine model of drug induced arrhythmias. Br J Pharmacol 161:1444-1454

26. Antzelevitch C, Sicouri S, Di Diego JM, Burashnikov A, Viskin S, Shimizu W, Yan GX, Kowey P, Zhang L. Does TpeakTend provide an index of transmural dispersion of repolarization? Heart Rhythm 2007;4:1114-6; author reply $1116-9$.

27. Opthof T, Coronel R, Wilms-Schopman FJ, Plotnikov AN, Shlapakova IN, Danilo P Jr, Rosen MR, Janse MJ (2007) Dispersion of repolarization in canine ventricle and the electrocardiographic T wave: Tp-e interval does not reflect transmural dispersion. Heart Rhythm 4:341-348

28. Piktel JS, Jeyaraj D, Said TH, Rosenbaum DS, Wilson LD (2011) Enhanced dispersion of repolarization explains increased arrhythmogenesis in severe versus therapeutic hypothermia. Circ Arrhythm Electrophysiol 4:79-86

29. Kim SM, Hwang GS, Park JS, Shin JS, Kim GW, Yang HM, Choi SY, Yoon MH, Shin JH, Tahk SJ (2014) The pattern of Tpeak-Tend and QT interval, and J wave during therapeutic hypothermia. J Electrocardiol 47:84-92

30. Hsieh YC, Lin SF, Huang JL, Hung CY, Lin JC, Liao YC, Lo CP, Wang KY, Wu TJ (2014) Moderate hypothermia (33 degrees C) decreases the susceptibility to pacing-induced ventricular fibrillation compared with severe hypothermia (30 degrees C) by attenuating spatially discordant alternans in isolated rabbit hearts. Acta Cardiol Sin 30:455-465

31. Boddicker KA, Zhang Y, Zimmerman MB, Davies LR, Kerber RE (2005) Hypothermia improves defibrillation success and resuscitation outcomes from ventricular fibrillation. Circulation 111:3195-3201

32. Egorov YV, Glukhov AV, Efimov IR, Rosenshtraukh LV (2012) Hypothermia-induced spatially discordant action potential duration alternans and arrhythmogenesis in nonhibernating versus hibernating mammals. Am J Physiol-Heart Circ Physiol 303:H1035-H1046 
33. Haugaa KH, Grenne BL, Eek CH, Ersboll M, Valeur N, Svendsen JH, Florian A, Sjoli B, Brunvand H, Kober L, Voigt JU, Desmet W, Smiseth OA, Edvardsen T (2013) Strain echocardiography improves risk prediction of ventricular arrhythmias after myocardial infarction. JACC Cardiovasc Imaging 6:841-850

34. Leren IS, Hasselberg NE, Saberniak J, Haland TF, Kongsgard E, Smiseth OA, Edvardsen T, Haugaa KH (2015) Cardiac mechanical alterations and genotype specific differences in subjects with long QT syndrome. JACC CardiovasC Imaging 8:501-510

35. Stankovic I, Putnikovic B, Janicijevic A, Jankovic M, Cvjetan R, Pavlovic S, Kalezic-Radmili T, Panic M, Milicevic P, llic I, Cvorovic V, Neskovic AN (2015) Myocardial mechanical and QTC dispersion for the detection of significant coronary artery disease. Eur Heart J Cardiovasc Imaging 16:1015-1022

36. Mikkelsen ME, Christie JD, Abella BS, Kerlin MP, Fuchs BD, Schweickert WD, Berg RA, Mosesso VN, Shofer FS, Gaieski DF (2013) Use of therapeutic hypothermia after in-hospital cardiac arrest. Crit Care Med 41:1385-1395

37. Bradley SM, Liu W, MCNally B, Vellano K, Henry TD, Mooney MR, Burke MN, Brilakis ES, Grunwald GK, Adhaduk M, Donnino M, Girotra S, for the Cardiac Arrest Registry to Enhance Survival Surveillance G (2018) Temporal trends in the use of therapeutic hypothermia for Out-of-Hospital Cardiac Arrest. JAMA Netw Open 1:e184511-e184511

38. Van Deuren B, Van Ammel K, Somers Y, Cools F, Straetemans R, van der Linde HJ, Gallacher DJ (2009) The fentanyl/ etomidate-anaesthetised beagle (FEAB) dog: a versatile in vivo model in cardiovascular safety research. J Pharmacol Toxicol Methods 60:11-23

39. Hotvedt R, Platou ES, Koppang ER, Refsum H (1982) Pentobarbital plasma concentrations and cardiac electrophysiology during prolonged pentobarbital infusion anaesthesia in the dog. Acta Anaesthesiol Scand 26:638-642

40. Nagasaki G, Tanaka M, Nishikawa T (2001) The recovery profile of baroreflex control of heart rate after isoflurane or sevoflurane anesthesia in humans. Anesth Analg 93:1127-1131

41. Kilkenny C, Browne WJ, Cuthill IC, Emerson M, Altman DG (2010) Improving bioscience research reporting: the ARRIVE guidelines for reporting animal research. PLoS Biol 8:e1000412

\section{Publisher's Note}

Springer Nature remains neutral with regard to jurisdictional claims in published maps and institutional affiliations.

\section{Submit your manuscript to a SpringerOpen ${ }^{\odot}$ journal and benefit from:}

- Convenient online submission

- Rigorous peer review

- Open access: articles freely available online

- High visibility within the field

- Retaining the copyright to your article

Submit your next manuscript at $\boldsymbol{\Delta}$ springeropen.com 